\title{
Prosthesis-Patient Mismatch after Surgical Aortic Valve Replacement: Neither Uncommon nor Harmless
}

Sérgio da Costa Rayol 1,2, MD; Michel Pompeu Barros Oliveira Sá1-3, MD, MSc, PhD; Luiz Rafael Pereira Cavalcanti 1,2, MD; Felipe Augusto Santos Saragiotto ${ }^{1,2}$, MD; Roberto Gouvea Silva Diniz ${ }^{1,2}$, MD; Frederico Browne Correia de Araujo e Sá1,2, MD; Alexandre Motta Menezes ${ }^{1,2}$, MD; Frederico Pires Vasconcelos Silva ${ }^{1,2}$, MD; Ricardo Carvalho Lima $^{1-3}, \mathrm{MD}, \mathrm{MSc}$, PhD, ChM, AATS

DOI: $10.21470 / 1678-9741-2019-0008$

\begin{abstract}
Prosthesis-patient mismatch (PPM) after surgical aortic valve replacement (SAVR) is an issue that has been overlooked (not to say neglected). Cardiac surgeons must bear in mind that this is a real problem that we must tackle. The purpose of this paper is to be a wake-up call to the surgical community by giving a brief overview of what PPM is, its incidence and impact on the
\end{abstract}

outcomes. We also discuss the increasing role played by imaging for predicting and assessing PPM after SAVR (with which surgeons must become more acquainted) and, finally, we present some options to avoid PPM after the surgical procedure.

Keywords: Aortic Valve Stenosis - Surgery. Heart Valve Prosthesis Implantation. Risk Assessment. Treatment Outcome.

\begin{tabular}{ll}
\hline \multicolumn{2}{l}{ Abbreviations, acronyms \& symbols } \\
\hline BSA & $=$ Body surface area \\
EOA & $=$ Effective orifice area \\
HF & $=$ Heart failure \\
LV & $=$ Left ventricle \\
MDCT & $=$ Multidetector computed tomography \\
PPM & $=$ Prosthesis-patient mismatch \\
SARE & $=$ Surgical aortic root enlargement \\
SAVR & $=$ Surgical aortic valve replacement \\
TAVR & $=$ Transcatheter aortic valve replacement \\
\hline
\end{tabular}

\section{Prosthesis-Patient Mismatch: Defining the Problem}

The objective of surgical aortic valve replacement (SAVR) is to replace the severely impaired native valve with a prosthesis that does not show any residual stenosis or regurgitation to relieve the pressure and/or left ventricular volume overload. Unfortunately, the hemodynamic profile of most prostheses do not live up to that of a normal native valve, and a non-negligible proportion of patients in the postoperative period have high

'Department of Cardiovascular Surgery at Pronto-Socorro Cardiológico de Pernambuco (PROCAPE), Recife, PE, Brazil.

2Universidade de Pernambuco (UPE), Recife, PE, Brazil.

${ }^{3}$ Nucleus of Postgraduate Studies and Research in Health Sciences at Faculdade de Ciências Médicas and Instituto de Ciências Biológicas (FCM/ICB), Recife, PE, Brazil.

This study was carried out at the Department of Cardiovascular Surgery at ProntoSocorro Cardiológico de Pernambuco (PROCAPE), Recife, PE, Brazil. residual transprosthetic pressure gradients due to prosthesispatient mismatch (PPM) ${ }^{[1]}$.

PPM refers to a prosthetic valve that is functioning normally, but whose effective orifice area (EOA) is too small in relation to the patient's body surface area and, therefore, to cardiac output requirements. In view of this, PPM is defined based on the indexed prosthetic valve EOA to the patient's body surface area (BSA), and it is considered non-existent or not clinically significant when the indexed EOA (iEOA) is $>0.85 \mathrm{~cm}^{2} / \mathrm{m}^{2}$, moderate when it is between 0.65 and $0.85 \mathrm{~cm}^{2} / \mathrm{m}^{2}$ and severe when $<0.65 \mathrm{~cm}^{2} / \mathrm{m}^{2[1]}$.

\section{What Is the Incidence of PPM After SAVR?}

Fallon et al. ${ }^{[2]}$ and Sá et al. ${ }^{[3]}$ published the largest studies showing the incidence of PPM after SAVR and both showed that PPM is not an uncommon problem.

Using the STS Adult Cardiac Surgery Database, Fallon et al.[.2] recently observed that, among 59,779 patients undergoing SAVR, the incidence of PPM was $46.8 \%$ for moderate PPM and $6.2 \%$ for severe PPM, which means that, even in the USA, more than $50 \%$ of the patients still leave the operating room with a considerable degree of PPM. Similarly, Sá et al. ${ }^{[1]}$ recently

Correspondence Address:

Michel Pompeu Barros Oliveira Sá

(iD) https://orcid.org/0000-0001-5356-2996

Pronto-Socorro Cardiológico de Pernambuco - PROCAPE

Department of Cardiovascular Surgery

Rua dos Palmares S/N - Santo Amaro, Recife, Pernambuco

Zip code: 74970-240

E-mail: michel_pompeu@yahoo.com.br

Article received on January $11^{\text {th }}, 2019$. Article accepted on February $28^{\text {th }}, 2019$. 
published a systematic review with meta-analysis including 70 articles and 108,182 patients and observed a 53.7\% incidence of moderate/severe PPM after AVR, ranging from 6.1\% to 93.8\%.

\section{What Is the Impact of PPM After SAVR?}

It is noteworthy that both Fallon et al. ${ }^{[2]}$ and Sá et al. ${ }^{[3]}$ highlighted that not only severe, but also moderate PPM has a negative impact on mortality rates after SAVR. Hazard ratios presented by Fallon et al. ${ }^{[2]}$ confirmed the escalating risk of death with increasing severity of PPM. Patients with moderate and severe PPM in comparison to those with no PPM had an $8 \%$ and $32 \%$ increase in relative risk of mortality, respectively. There was a $22 \%$ increase in relative risk of mortality between severe and moderate PPM. The risk of readmission for heart failure (HF) in ten years increased with the increasing severity of PPM. Patients with moderate and severe PPM had a 15\% and 37\% increased risk of readmission for HF compared to those with none. There was a 19\% increased risk of readmission for HF in severe versus moderate PPM. There was a notable increase in readmission for $\mathrm{HF}$ in people with moderate PPM (19.7\%) in ten years. Fallon et al. $^{[3]}$ highlighted this was most notable in those with severe PPM, in whom there was a nearly three-fold increased risk of redo aortic valve replacement compared to those with no PPM. Figure 1 shows the adjusted survival rates in the STS Adult Cardiac Surgery Database for patients after SAVR according to the absence/presence of PPM.

Sá et al. ${ }^{[3]}$ demonstrated that patients with moderate/severe PPM have higher risk of perioperative, 1-year, 5-year and 10-year mortality rates in comparison to those with non-significant/no PPM (Figure 2). Moreover, mortality rates increased not only with severe PPM, but also with moderate PPM, being severe PPM even worse than moderate in terms of mortality rates. Some studies also showed that PPM is also associated with faster structural degeneration of bioprosthetic valves following $\operatorname{SAVR}^{[4,5]}$.

\section{Role of Imaging for Predicting and Assessing PPM After SAVR}

Pibarot et al. ${ }^{[6]}$ state that PPM is characterized by high transprosthetic velocity and gradients, normal EOA, small indexed EOA, and normal morphology and mobility of leaflets. Transthoracic or transesofageal echocardiography (TTE or TEE) with Doppler is the basis of the diagnosis and quantification of PPM, but other imaging modalities, such as multidetector computed tomography (MDCT), may provide important complementary information regarding the prediction and assessment of PPM ${ }^{[6]}$.

Table 1 shows the role of imaging for differential diagnosis between normal prosthetic valve, PPM and prosthetic stenosis. Cardiac surgeons must be well acquainted with these concepts to be able to take part in the decision-making process to solve this problem when it arises.

\section{Avoiding PPM after SAVR}

Taking into consideration the negative impact of PPM on survival, functional recovery, rates of hospitalization for HF and valve durability, planning to avoid PPM is of paramount importance. Severe PPM should be prevented in every patient undergoing SAVR, whereas moderate PPM should be avoided mostly in vulnerable subsets such as patients with impaired left ventricular ejection fraction; severe left ventricular hypertrophy; low-flow, low-gradient aortic stenosis; or concomitant mitral regurgitation. To adopt preventive strategies, the cardiac surgeon must predict, before prosthesis implantation, the required iEOA after SAVR, which decreases the risk of significant PPM.

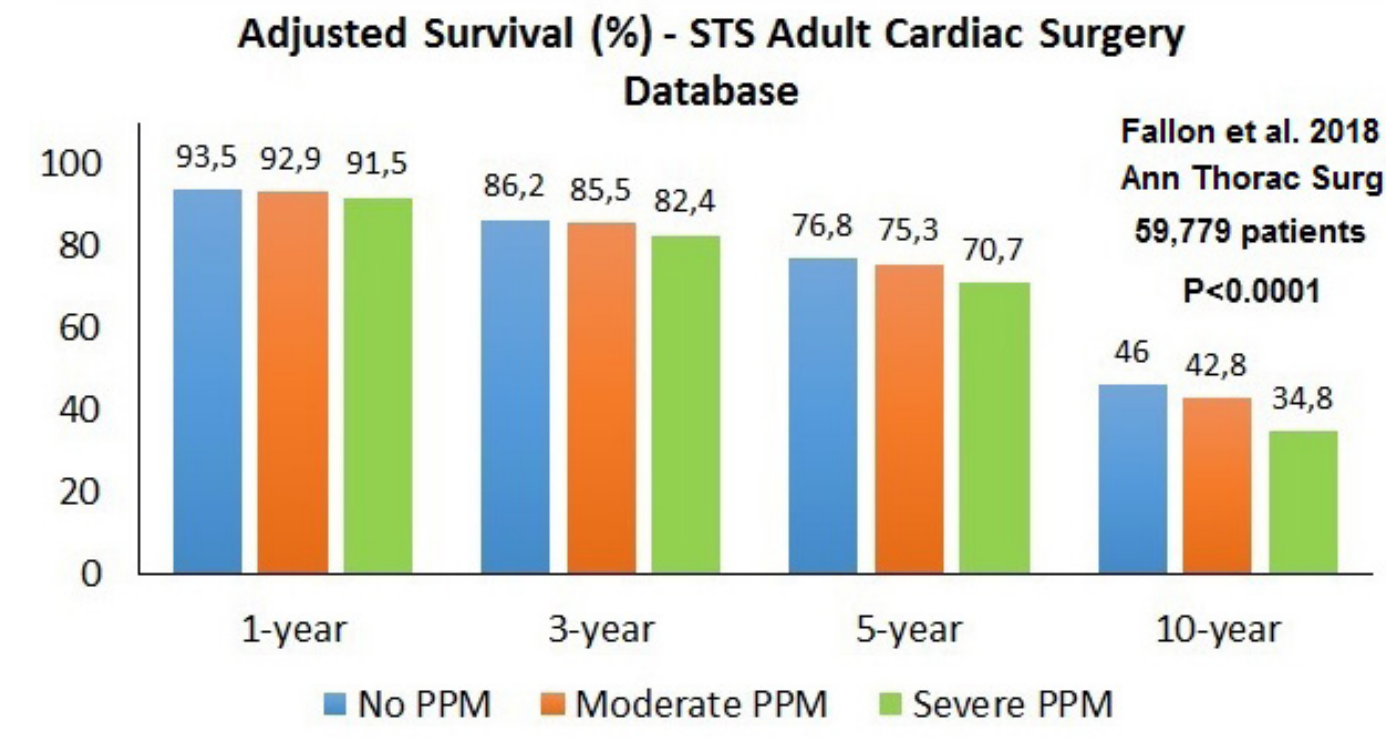

Fig. 1 - Survival rates - STS Adult Cardiac Surgery Database. 


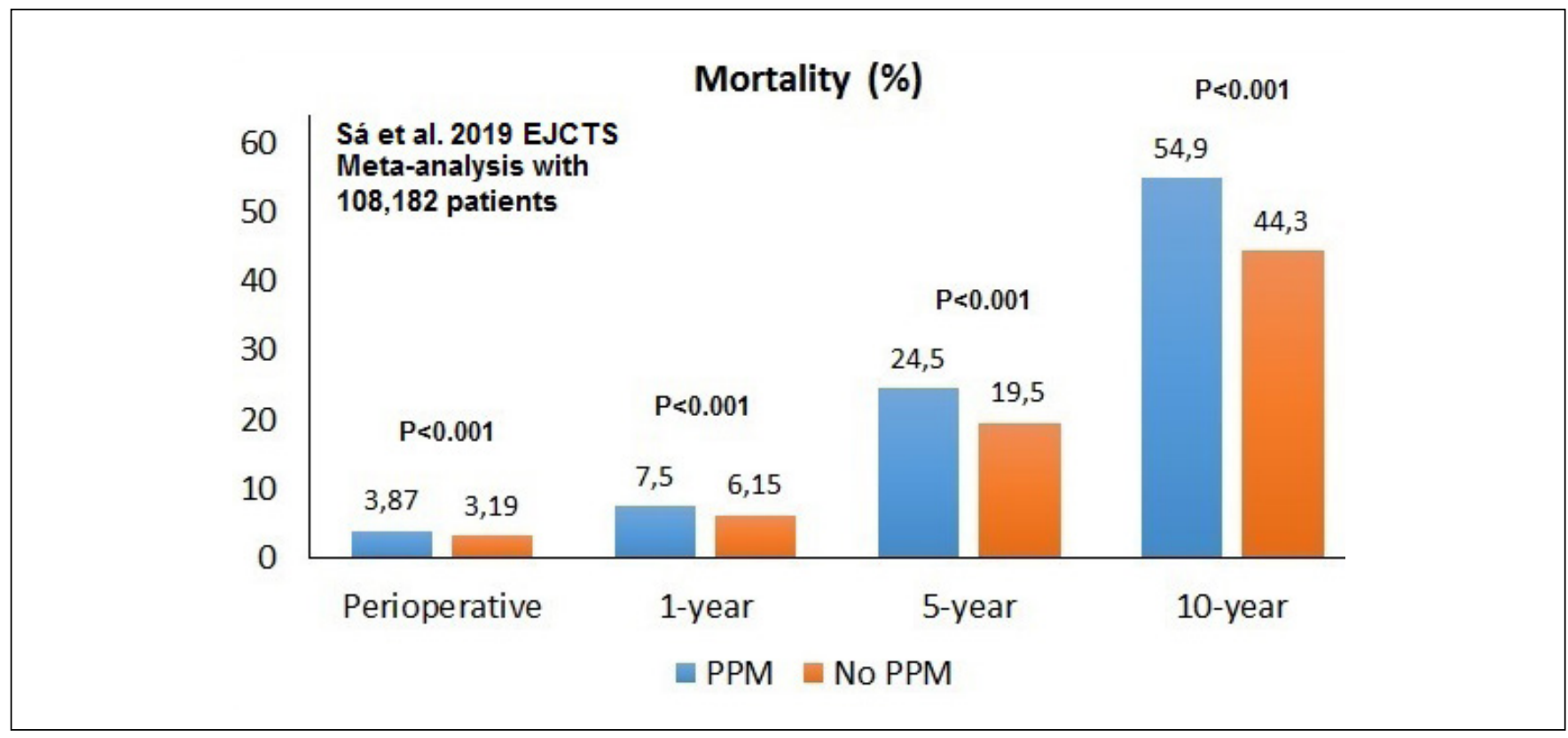

Fig. 2 -Mortality rates - Largest meta-analysis published up to now.

To obtain the predicted iEOA of surgical prostheses, the cardiac surgeon needs to know the model and size of the prosthesis that to be implanted. Then, the surgeon should refer to the tables that include the normal EOAs for the different models and label sizes of surgical prosthetic valves and divide the normal EOA by the patient's BSA. This process can be done intraoperatively, once the debridement and measurement of the aortic annulus are made or preoperatively by measuring the aortic annulus dimensions by MDCT or TEE. A word of caution: the prediction of valve size from the aortic annulus size measured by imaging before SAVR will not take into account the valve excision and the annulus debridement performed by the surgeon at the time of SAVR.

A predicted iEOA $\leq 0.65 \mathrm{~cm}^{2} / \mathrm{m}^{2}$ (or $\leq 0.55 \mathrm{~cm}^{2} / \mathrm{m}^{2}$ in obese patients) indicates a risk of severe PPM, whereas an iEOA $\leq 0.85$ $\mathrm{cm}^{2} / \mathrm{m}^{2}$ (or $\leq 0.70 \mathrm{~cm}^{2} / \mathrm{m}^{2}$ in obese patients) is consistent with a risk of moderate PPM.

If severe or moderate PPM in vulnerable patients is foreseen from the predicted iEOA calculation, several preventive strategies can be adopted.

As a first option, the surgeon may choose to implant another model of prosthetic valve providing a larger EOA for a given

Table 1. Imaging for differential diagnosis between normally functioning aortic prosthesis, prosthesis-patient mismatch and prosthetic stenosis (proposed by Pibarot et al. ${ }^{[6]}$ ).

\begin{tabular}{|c|c|c|c|}
\hline Variable & $\begin{array}{l}\text { Normally functioning } \\
\text { prosthesis }\end{array}$ & $\begin{array}{l}\text { Prosthesis-patient } \\
\text { mismatch }\end{array}$ & $\begin{array}{l}\text { Prosthetic valve } \\
\text { stenosis }\end{array}$ \\
\hline Peak transprothetic aortic velocity $(\mathrm{m} / \mathrm{s})$ & $<3$ & $\geq 3$ & $\geq 3$ \\
\hline Mean transprothetic measure gradient (mmHg) & $<20$ & $\geq 20$ & $\geq 20$ \\
\hline Effective orifice area $\left(\mathrm{cm}^{2}\right)$ & $>1$ & $>1$ & variable \\
\hline Doppler velocity index ${ }^{*}$ & $\geq 0.35$ & $0.25-0.34$ & $<0.25$ \\
\hline Indexed effective orifice area $\left(\mathrm{cm}^{2} / \mathrm{m}^{2}\right)$ & $>0.85$ & $\leq 0.85$ & $\leq 0.85$ \\
\hline $\begin{array}{l}\text { Increase in mean transprosthetic measure gradient } \\
(\mathrm{mmHg}) \text { during follow-up }\end{array}$ & $<10$ & $<10$ & $\geq 10$ \\
\hline Decrease in effective orifice area during follow-up $\left(\mathrm{cm}^{2}\right)$ & $<0.3$ & $<0.3$ & $\geq 3$ \\
\hline Acceleration time (milliseconds) & $<80$ & $<80$ & $\geq 80$ \\
\hline Acceleration time/left ventricle ejection time ratio & $<0.32$ & $<0.32$ & $\geq 0.32$ \\
\hline
\end{tabular}

*The Doppler velocity index is the ratio of the left ventricular outflow tract velocity time integral to transprosthetic flow velocity time integral. 
aortic annulus size (e.g., a stentless or sutureless prosthesis vs. a stented prosthesis).

As a second option, transcatheter aortic valve replacement (TAVR) may be considered instead of SAVR. For this strategy, it would be important to predict PPM before the surgical procedure. Imaging is essential to identify patients with a small aortic annulus in whom it would be difficult to implant a medium or large prosthetic valve during SAVR, even with extensive annulus debridement. In such patients, TAVR may be considered. The VIVA trial (ClinicalTrials.gov; NCT03383445) is currently ongoing to compare TAVR versus SAVR in elderly patients with severe aortic stenosis and a small aortic annulus.

The first and second options are problematic in the developing world. We must highlight that not all the countries in the world can afford the so-called "new generation" prostheses with a better profile nor easy access to TAVR. In the largest country in Latin America (Brazil), for example, more than $90 \%$ of patients are operated on in public health care centers, where patients cannot receive these new generation prostheses or TAVR simply because they are not available in the system owing to the price. It is a very different reality. When it comes to these new models of prostheses (including stentless, sutureless and transcatheter valves), they may well be the reality in Europe and North America, but not within the public health systems in Latin America (including Brazil), Africa and most part of Asia, where surgeons have to work with other types of prostheses of "older" technology.

As a third option, the cardiac surgeon may perform a surgical aortic root enlargement or (SARE) aortic annular enlargement to accommodate a larger size of the stented bioprosthesis. This more invasive strategy should be adopted only if the anatomy of the aortic root is favorable and the risk-benefit ratio of this concomitant procedure is considered reasonable.

\section{SARE As an Option Within Reach of Any Surgeon}

Since SARE requires neither special devices nor advanced technologies, cardiac surgeons must consider this technique as a possibility when it comes to avoiding PPM after SAVR.

Sá et al. ${ }^{[7]}$ published the first systematic review with metaanalysis including 10 articles and 13,174 patients demonstrating that, overall, patients who underwent SAVR with SARE have statistically significant higher risk of perioperative mortality in comparison to those without ARE, but not without concomitant procedures (actually, they also observed a higher risk, but the difference was statistically non-significant). They also observed that, despite longer cardiopulmonary bypass and aortic cross-clamping times, patients who underwent SAVR with SARE did not experience higher rates of myocardial infarction, stroke, complete heart block/permanent pacemaker implantation and reoperation for bleeding. On the other hand, patients who underwent SAVR with SARE had higher overall mean of $\mathrm{iEOA}$ and lower overall rate of PPM.

Rocha et al. ${ }^{[8]}$ showed that SARE did not increase the operative mortality of SAVR among 7,039 patients (SAVR, $\mathrm{n}=5185$; SAVR+SARE, $\mathrm{n}=1854$ ). In-hospital mortality was actually higher in the latter group (3.0\% vs. $4.3 \%, P=0.008)$, but when the cohort was restricted to isolated SAVR with or without SARE, mortality was not statistically significant different (1.1\% vs. 1.7\%, $P=0.290)$. Following adjustment for baseline characteristics, SAVR+SARE was not associated with an increased risk of in-hospital mortality when compared with SAVR (OR 1.030, $P=0.850$ ). Results were also similar when propensity matching was used for baseline characteristics. Correia et al. ${ }^{[9]}$, Penaranda et al.. ${ }^{[10]}$ and Dhareshwar et al. ${ }^{[1]}$ also found that SARE does not increase mortality in the context of SAVR.

\section{CONCLUSION}

PPM is a frequent complication of SAVR, which is associated with increased risk of structural valve degeneration, hospitalization for HF, and mortality. The risk of PPM can be foreseen before SAVR by calculating the predicted index from the normal reference value of EOA of the prosthesis and patient's BSA.

Severe symptomatic PPM following SAVR with a bioprosthetic valve may be treated by redo surgery or transcatheter valveinvalve procedure cracking the surgical valve stent, but this is another subject yet to be explored.

\section{No financial support. No conflict of interest.}

\section{Authors' roles \& responsibilities}

$\mathrm{SCR}$

Substantial contributions to the conception or design of the work; or the acquisition, analysis, or interpretation of data for the work; final approval of the version to be published

MPBOS Substantial contributions to the conception or design of the work; or the acquisition, analysis, or interpretation of data for the work; final approval of the version to be published

LRPC Substantial contributions to the conception or design of the work; or the acquisition, analysis, or interpretation of data for the work; final approval of the version to be published

FASS Substantial contributions to the conception or design of the work; or the acquisition, analysis, or interpretation of data for the work; final approval of the version to be published

RGSD Substantial contributions to the conception or design of the work; or the acquisition, analysis, or interpretation of data for the work; final approval of the version to be published

FBCAS Substantial contributions to the conception or design of the work; or the acquisition, analysis, or interpretation of data for the work; final approval of the version to be published

AMM Substantial contributions to the conception or design of the work; or the acquisition, analysis, or interpretation of data for the work; final approval of the version to be published

FPVS Substantial contributions to the conception or design of the work; or the acquisition, analysis, or interpretation of data for the work; final approval of the version to be published

RCL Substantial contributions to the conception or design of the work; or the acquisition, analysis, or interpretation of data for the work; final approval of the version to be published 


\section{REFERENCES}

1. Pibarot P, Clavel MA. Prosthesis-patient mismatch after transcatheter aortic valve replacement: it is neither rare nor benign. J Am Coll Cardiol. 2018;72(22):2712-6. doi:10.1016/j.jacc.2018.09.045.

2. Fallon JM, DeSimone JP, Brennan JM, O'Brien S, Thibault DP, DiScipio AW, et al. The incidence and consequence of prosthesis-patient mismatch after surgical aortic valve replacement. Ann Thorac Surg. 2018;106(1):1422. doi:10.1016/j.athoracsur.2018.01.090.

3. Sá MPBO, Carvalho MMB, Sobral Filho DC, Cavalcanti LRP, Diniz RGS, Rayol SC, et al. Surgical aortic valve replacement and patient-prosthesis mismatch: meta-analysis of 108,182 patients. Eur J Cardiothorac Surg. 2019. doi:10.1093/ejcts/ezy466.

4. Flameng W, Herregods MC, Vercalsteren M, Herijgers P, Bogaerts K, Meuris B. Prosthesis-patient mismatch predicts structural valve degeneration in bioprosthetic heart valves. Circulation. 2010;121(19):2123-9. doi:10.1161/CIRCULATIONAHA.109.901272.

5. Mahjoub H, Mathieu P, Larose É, et al. Determinants of aortic bioprosthetic valve calcification assessed by multidetector CT. Heart. 2015;101(6):472-7. doi:10.1136/heartjnl-2014-306445.

6. Pibarot P, Magne J, Leipsic J, Côté N, Blanke P, et al. Imaging for predicting and assessing prosthesis-patient mismatch after aortic valve replacement. JACC
Cardiovasc Imaging. 2019;12(1):149-62. doi:10.1016/j.jcmg.2018.10.020.

7. Sá MPBO, Carvalho MMB, Sobral Filho DC, Cavalcanti LRP, Diniz RGS, Rayol SC, Soares AMMN, Sá FBCA, Menezes AM, Clavel MA, Pibarot P, Lima RC. Impact of surgical aortic root enlargement on the outcomes of aortic valve replacement: a meta-analysis of 13174 patients. Interact Cardiovasc Thorac Surg. 2019. doi: 10.1093/icvts/ivy364.

8. Rocha RV, Manlhiot C, Feindel CM, Yau TM, Mueller B, David TE, et al. Surgical enlargement of the aortic root does not increase the operative risk of aortic valve replacement. Circulation. 2018;137(15):1585-94. doi:10.1161/CIRCULATIONAHA.117.030525.

9. Correia PM, Coutinho GF, Branco C, Antunes MJ. Long-term follow-up of patients undergoing aortic root enlargement for insertion of a larger prosthesis. Eur J Cardiothorac Surg. 2016;50(1):82-8. doi:10.1093/ ejcts/ezv487.

10. Penaranda JG, Greason KL, Pislaru SV, Schaff HV, Daly RC, Park SJ, et al. Aortic root enlargement in octogenarian patients results in less patient prosthesis mismatch. Ann Thorac Surg. 2014;97(5):1533-8. doi:10.1016/j. athoracsur.2013.11.050.

11. Dhareshwar J, Sundt TM 3rd, Dearani JA, Schaff HV, Cook DJ, Orszulak TA. Aortic root enlargement: what are the operative risks? J Thorac Cardiovasc Surg. 2007;134(4):916-24. doi:10.1016/j.jtcvs.2007.01.097. 